\title{
Desarrollo geográfico desigual y crisis de la Unión Europea: Conferencia a cargo del Doctor Costis Hadjimichalis
}

\author{
Costis Hadjimichalis \\ Departamento de Geografía. Universidad Harokopio de Atenas, \\ Grecia
}

\section{Introducción del CoOrdinador, Dr. Jerónimo Montero Bressan:}

Uno de los principales teóricos del neoliberalismo es el geógrafo Jamie Peck, quien identifica el origen del neoliberalismo en las ideas gestadas en la Mont Pellerin Society de París en la década de 1940. Peck muestra cómo Milton Friedman, Von Hayek y otros hicieron un trabajo de hormiga, viajando alrededor del mundo para promover las ideas neoliberales en ámbitos de decisión política clave, como partidos políticos, círculos empresariales y notablemente en las universidades también. En un marco de fuerte legitimidad de las políticas favorables al Estado de Bienestar, se dedicaron a promocionar las ideas neoliberales para que esas ideas estuvieran sobre la mesa cuando finalmente se llegara a la crisis del fordismo que ellos predecían. Eso ocurrió a fines de los 1960, principios de los 1970. La situación de crisis obligó a los círculos de decisión política a echar mano a las diversas ideas acerca de la regulación de la economía, lo que dio lugar a las ideas neoliberales, que finalmente tomaron un papel protagónico en ese contexto. Estas ideas finalmente se ponen en práctica en primer lugar en América Latina, región que, según David Harvey, fue el laboratorio de las políticas neoliberales.

Ahora, estas políticas se aplicaron de diversas maneras en diversas regiones y países. Sería interesante que en la conferencia del profesor Hadjimichalis prestemos atención a las diferencias entre cómo se impusieron en nuestra región y en Europa. En el primer caso, hubo actores que operaban a escala internacional que contribuyeron a imponer el neoliberalismo a través del autoritarismo, es decir, que hubo apoyo militar y financiero desde el exterior, e incluso hubo una clara vinculación entre los ministros de economía de la región con los propios teóricos neoliberales, como el caso del ministro de Economía de Pinochet con Milton Friedman. A escala nacional nuestras burguesías también se vieron favorecidas por estos eventos, fuera por la represión a los obreros y el disciplinamiento de los sindicatos, por la habilitación de negocios financieros, o por la estatización de deuda.

Hay entonces numerosas similitudes entre el rol de los organismos internacionales y de las burguesías nacionales en América Latina y en Europa. Sin embargo, en el segundo caso la neoliberalización se dio a partir de la creación de un nuevo híbrido espacio-escala que fue la UE, y en particular la Eurozona. Las particularidades de este caso y su comparación con el de nuestra región pueden decirnos mucho acerca del neoliberalismo y de cómo operan los organismos internacionales y las empresas multinacionales.

Costis nos va a hablar ahora de los capítulos 2 y 3 de su libro más reciente, llamado Crisis Spaces: Structures, Struggles and Solidarity in Southern Europe [Espacios de crisis: estructuras, luchas y solidaridades en el sur de Europa, 2017, Routledge, Londres]. En el libro el autor brinda una sólida explicación de largo plazo acerca de las causas de la crisis en los países del sur europeo. Costis es profesor emérito en la Universidad Harokopio de Atenas, hizo su carrera de grado en planificación urbana y sólo más tarde llegó a la geografía a través de Edward Soja, con quien hizo el doctorado en Los Ángeles. Ahora hace muchos años que trabaja en Grecia, antes en la Universidad de Tesalónica y ahora en Atenas, en uno de los epicentros de la crisis. 


\section{Conferencia de Costis Hadjimichalis}

Déjenme comenzar agradeciéndoles a todos ustedes por estar aquí y a los organizadores, a Jerónimo por invitarme y a la intérprete. Estando en el ámbito de la geografía, pienso hablarles del desarrollo geográfico desigual, que es algo muy conocido por ustedes, a partir de vuestra propia experiencia, aquí y en América Latina.

Como ustedes saben muy bien, el desarrollo desigual es un concepto marxista, pero el mismo Marx no dijo mucho al respecto. Marx habló de muchas formas de desigualdad, en términos del proceso de acumulación y de competencia entre distintas facciones del capital, pero nunca mencionó el espacio. En la mayor parte de su obra, particularmente en los tres volúmenes de El Capital, así como en el Manifiesto Comunista, él planteaba que el mercado mundial volvería prácticamente homogéneas las condiciones de desigualdad entre países. Esta posición fue retomada luego por Rosa Luxemburgo, que sostenía que si el capitalismo llegaba a gobernar el mundo entero, entonces llegaría a su fin, y se daría el advenimiento del socialismo. León Trotsky propuso en los años 1920 la ley del desarrollo desigual y combinado, y con esta ley dio un gran paso para comprender al desarrollo, no como un proceso individual de países específicos, sino como combinado y dependiente.

Todos los abordajes sobre desarrollo desigual que acabo de mencionar derivaron de alguna manera de la filosofía del siglo XIX, que se caracterizó por la subordinación del espacio ante la historia, ante la historicidad, una gran limitación, responsable de eliminar la imaginación espacial del pensamiento de Marx, lo cual se ve incluso en la actualidad. Por lo que conozco de muchos camaradas marxistas en Europa, hasta el día de hoy la geografía y el espacio son algo así como un entorno externo, y como el propio Marx dijo, una "complicación innecesaria". Todos ellos trataron al espacio como una especie de contenedor físico, como la suma de los lugares de producción y de exportación de recursos, el territorio de los distintos mercados, todo dependiente de la fricción de la distancia.

Una figura particular, especialmente para el sur de Europa y luego para el resto del mundo, es la de Antonio Gramsci. Su trabajo sobre historia y geografía, tiempo y espacio ha sido una gran influencia para todos los geógrafos radicales hasta el día de hoy. Con su énfasis en el ensamble de relaciones, que compromete una historia particular, una geografía particular, una sociedad particular, ha sido un gran aporte teórico para la geografía radical, para la geografía marxista. Y tengo entendido que Milton Santos ha trabajado en esa línea. El paso de Gramsci hacia Henry Lefébvre, el famoso filósofo francés, es obvio, y es necesario en pos de la clarificación del elemento espacial en el desarrollo desigual. Lefébvre, como Gramsci, luchó consecuentemente contra el marxismo dogmático y reduccionista de su tiempo. Suya es la famosa tesis, que ustedes seguramente conocen, de la producción social del espacio. Él también desarrolló el argumento, en su libro sobre la supervivencia del capitalismo [La producción del espacio], de que el capitalismo ha sobrevivido todos estos años mediante la ocupación y producción de espacio. Éste fue el marco de referencia en el que luego de los años 1970 una nueva generación (ahora ya vieja) de geógrafos humanos surgió, como David Harvey, Eric Clark, Edward Soja, Neil Smith, Milton Santos en Latinoamérica, para desarrollar un pensamiento geográfico marxista radical que permitiera explicar el funcionamiento del mundo.

Y ahora tenemos el concepto de desarrollo geográfico desigual, que creo es de mucha ayuda para entender qué sucede en el mundo en la actualidad. Este marco teórico creo que nos sirve para comprender el surgimiento de la crisis europea. Porque la mayoría de los economistas explican la crisis en Europa, y particularmente en la zona euro, como un problema de deuda pública y privada. Por supuesto, este elemento existe, pero es bastante reciente. Para entender cómo surgió la crisis, es necesario volver varias décadas atrás en la historia. Esto es un anatema para los economistas neoliberales, que sólo ven lo que ellos llaman el "pasado corto”, que sólo implica cuatro años atrás, ocho como mucho, no más. Desde mi punto de vista, y el de la geografía radical, debemos ver cómo el sur de Europa fue integrado a la Unión Europea, cuál fue el proceso de esta integración, y cómo las fuerzas productivas y económicas locales fueron afectadas por este proceso de integración. 
Acá vale destacar que quienes planificaron la Unión Europea no tuvieron en cuenta el elemento espacial. Me pregunto por qué la unificación europea, sea a propósito o por ignorancia, ha subvaluado la importancia del espacio, de la geografía. Para mí es obvio que sólo alguien que no pensó realmente en integración podría haber cometido semejante error, el de no tener en cuenta seriamente el desarrollo desigual de las varias regiones y países que serían miembros de la UE. Uno podría decir que cuando comienza un proceso de integración no se puede tener en cuenta todo, que hay que poner ciertos elementos en la mesa para solucionar problemas. Es cierto que inmediatamente después de integración europea, especialmente tras la incorporación del Reino Unido, hubo un fuerte elemento de cohesión, de convergencia regional. Pero eso no fue suficiente. Si bien al comienzo hubo cierta convergencia entre las tasas de crecimiento del PBI o del empleo, enseguida nos dimos cuenta de que las diferencias y desigualdades regionales se incrementaron.

Piensen por un momento en España, que tal vez conozcan mejor que cualquier otro país europeo meridional, en cómo era su geografía económica en los años 1980. Era muy desigual. Quiero decir, teníamos una fuerte producción industrial en el País Vasco, que venía del siglo XIX; lo mismo sucedía en Cataluña; había un núcleo de pequeñas y medianas firmas en Valencia; Madrid no estaba totalmente industrializada; y el resto era gran área agrícola o de espacios vírgenes para el desarrollo de inversiones de grandes firmas industriales europeas y americanas. Era el período posterior al fin del régimen de Franco. Ustedes deben recordar muy bien que durante el franquismo se desarrollaron muchos polos industriales. Pero tratemos de ver este modelo también en Portugal, de alguna manera en Italia, particularmente en el sur, y en Grecia. Estos países, que vivieron dictaduras hasta los años 1970, para mediados de los años 1980 ya eran parte de lo que entonces era el Mercado Común Europeo.

Fue el período en el que tuvimos la primera crisis del petróleo, los primeros indicios de desindustrialización; por supuesto se daba la exportación de productos agrícolas hacia el Mercado Común Europeo, pero los países europeos también comenzaron a exportar más fácilmente los productos industriales de las economías más poderosas. Entonces, para fines de los 1980 las diferencias sociales y económicas entre la Europa del sur, y la Europa central y del norte se volvieron muy claras. Y luego del ingreso del Reino Unido se comenzó a aplicar la política original de la Unión Europea. En los años 1990 se introdujo el tratado de Maastricht, que fue la principal arma, el principal vehículo, para la institucionalización del neoliberalismo en Europa. Esto fue realmente catastrófico para la Europa meridional, porque cambió totalmente su modo de gobernanza económica. Se intentó imponer la flexibilización laboral en el mercado de trabajo ya de por sí flexible que existía en el sur de Europa. Y al mismo tiempo se produjo la privatización de las principales empresas de servicios públicos. Eso permitió que una generación nueva de capitalistas se volcara a la acumulación por desposesión, como señaló Harvey hace ya unos años. Y esta situación fue particularmente negativa para los países del sur de Europa, dado que tradicionalmente tenían un sector público fuerte y muchas compañías públicas productivas, no sólo energéticas, sino también industriales, astilleros, refinerías... Y todas esas compañías fueron privatizadas.

Entonces, para los primeros años 2000 estaba claro que teníamos un desarrollo geográfico desigual a lo largo de toda Europa, a lo largo de toda la Unión Europea. Y luego se introdujo el euro, y la zona euro se volvió un nuevo espacio, un espacio híbrido, una escala híbrida, absolutamente funcional y necesaria para la nueva fase del capitalismo que fue la financiarización. Todo el mundo en el sur de Europa empezó a imaginarse como un pasajero de clase business, y ya no como un ciudadano ordinario. Al tener una moneda fuerte, mucho más fuerte que las monedas nacionales que teníamos antes, se pensó “ $o k$, ya que tenemos un montón de euros, empecemos a importar más y a gastar más". Sólo para darles un ejemplo del caso griego, cada mañana yo iba a un bar a tomar un café y gastaba 100 dracmas; después de la introducción del euro, tenía que pagar 1,5 euros. Pero 1 euro era equivalente a 370 dracmas. Por lo tanto, de un día para el otro todo se volvió más caro, pero esto no fue comprendido por la mayoría de la población. Por el contrario, esto fue comprendido por los bancos, que empezaron a darle muchos préstamos a la gente, dado que había un exceso de capital, 
un flujo de capital del norte hacia el sur, que ya había empezado en los noventa, pero que se aceleró con la introducción del euro.

Entonces, con el paso del tiempo se dio una sobreacumulación de capital en ciertas regiones del centro y norte de Europa, particularmente Alemania, los Países Bajos, Austria, y algunas regiones de Francia; y, al mismo tiempo, una acumulación de deuda en la mayoría de las regiones del sur de Europa, y en el este, en los antiguos países socialistas. En este proceso, los estados del sur de Europa enfrentaron grandes dificultades debido la reducción de impuestos que promueven las políticas neoliberales, y la recaudación impositiva se redujo debido al bajo nivel de actividad productiva. O bien, los capitalistas locales exportaron su capital al mercado europeo, a bancos europeos o a paraísos fiscales. Entonces, hacia 2005, 2006, nos encontramos con el gran problema de la deuda pública y privada, medidas como porcentajes del PBI.

Debido a que el Banco Central Europeo (BCE) ha sido organizado bajo estrictas normas e ideología neoliberales, los países del sur no podíamos tomar más préstamos de éste como último recurso. Si bien otros bancos centrales en el mundo funcionan como prestadores de último recurso, el BCE no cumple esa función. Cuando la crisis de los Estados Unidos llegó a Europa alrededor de 2008 golpeó primero al eslabón más débil, que era Grecia, y para 2010 la burbuja inmobiliaria estalló. Por lo tanto, hasta ahora he tratado de argumentar por qué la deuda pública no es suficiente como explicación de lo que pasó en el sur de Europa y con la crisis en general en el continente. Pero cuando la crisis llegó, y cuando la Unión Europea junto con el Fondo Monetario Internacional y el Banco Central Europeo organizaron la llamada troika (porque eran tres diferentes fuerzas combinadas), comenzaron una fuerte guerra ideológica contra los pueblos del sur de Europa. Esto fue extremadamente importante, dado que intentaron legitimar las medidas de ultraausteridad que se estaban aplicando. Como sabemos, el neoliberalismo es una gran arma ideológica, porque controla un lenguaje y una simbología particulares. Fuimos acusados de amar la dolce vita, como en la viñeta que les estoy mostrando (figura 1). O bien usaron el acrónimo PIGS [cerdos, en inglés], que significa "Portugal, Italia, Grecia, España [Spain, en inglés]", y aquí podemos ver cómo los cerdos se comen el dinero europeo sin importarles nada (figura 2). Creo que estas dos imágenes, y otra que les voy a mostrar al final, ilustran la imagen general y el sentimiento de las diferentes culturas que se enfrentan ante un problema en Europa. Esta imaginación geográfica presenta dos polos diferentes: uno es el de la gente perezosa del sur de Europa, que no trabaja lo suficiente y gasta más de lo que puede producir, y el otro, el de los industriosos del centro y norte de Europa, que no gastan dinero y producen mucho. 
FIGURA 1.

Los europeos del sur viviendo la dolce vita mientras explota la crisis.

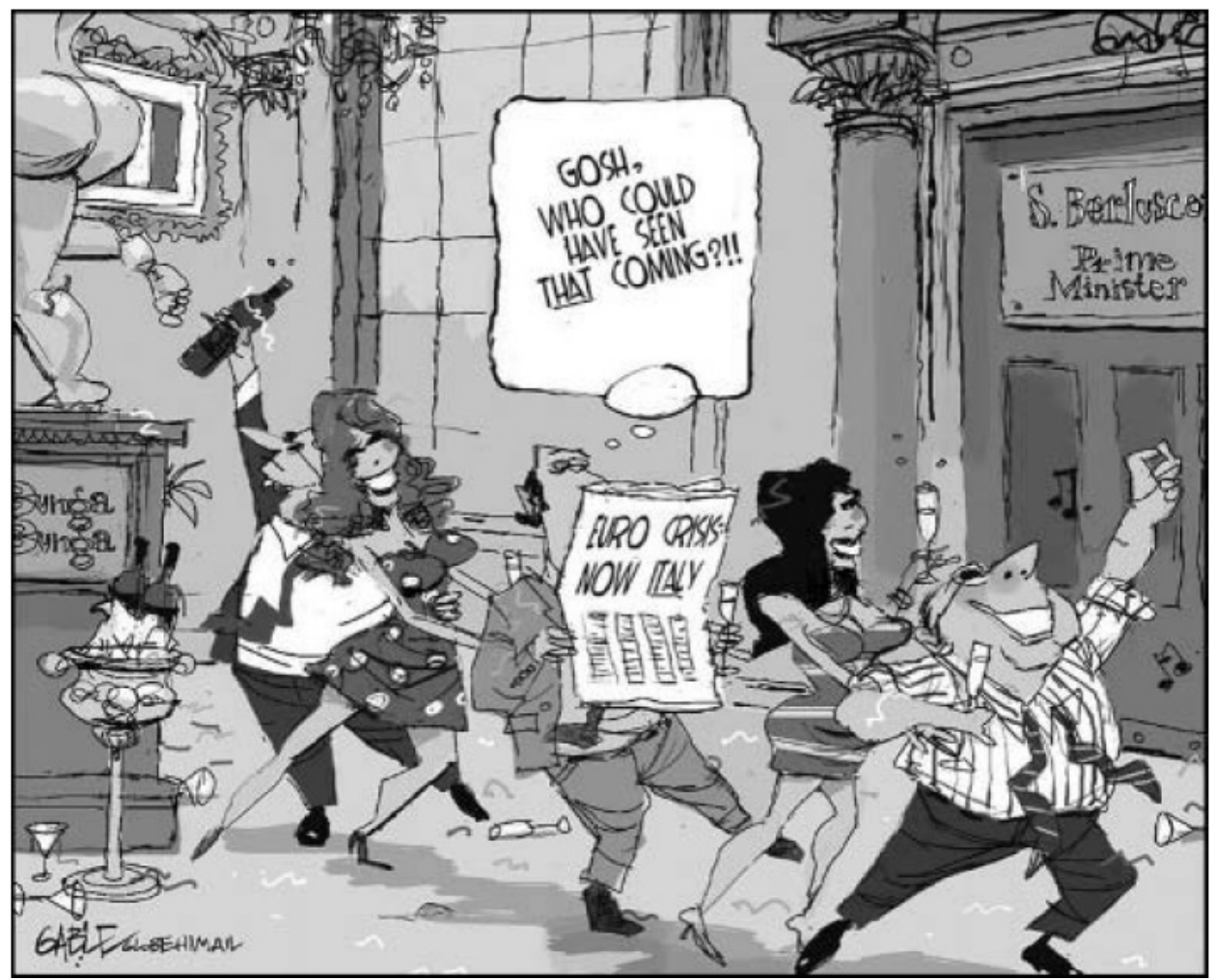

FIGURA 2

Los "cerdos" se comen el dinero de las arcas europeas

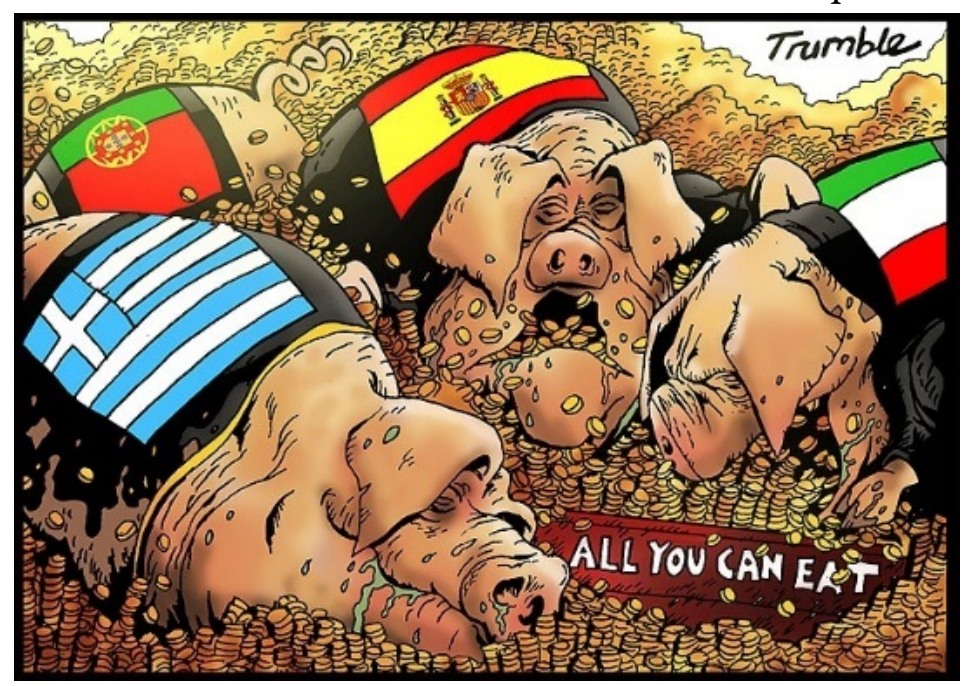

www.trumbleart.co.uk

Entonces, analicemos lo que hemos dicho hasta ahora. El primer punto es que los orígenes de la crisis están ligados al desarrollo geográfico desigual, que comenzó en los años ochenta. El segundo punto es que la deuda pública no es la causa única de la crisis, sino una de sus manifestaciones. El tercer punto es que las economías del sur de Europa participan, en diferentes grados, de una vasta transformación del capitalismo, que implica dejar atrás las actividades productivas e invertir en actividades especulativas basadas en la obtención de rentas, como el mercado de bienes raíces y la burbuja inmobiliaria en España, por ejemplo. Finalmente, como dijimos 
anteriormente, en el contexto de la hegemonía neoliberal, grupos y élites particulares en diferentes países, pero principalmente en Alemania, Países Bajos, Bélgica, parte de la burguesía francesa, y Austria, diseñaron los tratados de Ámsterdam y Maastricht para imponer no sólo el euro, sino también sus propios intereses económicos, políticos e ideológicos.

Como dije previamente, los países del sur de Europa entraron a la zona euro ya con estructuras económicas muy débiles. Inmediatamente, ya para mediados de los noventa, comenzaron a perder competitividad. Su situación se deterioró aún más con la introducción del euro en 2004, y ya en 2009, cuando empieza la crisis, vemos (como indica el gráfico 1) las diferencias entre Alemania (que sigue incrementando su competitividad) y los Países Bajos, Irlanda, España, Portugal, Italia, y sobre todo Grecia, que sufren una fuerte caída mayor de su competitividad.

Considerando todo esto, ustedes pueden preguntarse por qué los alemanes, por ejemplo, permitieron que los países del sur de Europa entraran al euro, ya que era evidente que iba a resultar una estructura muy inequitativa e inestable. La respuesta es obvia: el sur de Europa era el principal mercado para las exportaciones de Alemania. El gráfico 2 es un interesante diagrama que muestra que desde 1995 hasta 2007 (antes de la crisis) el sur de Europa es el mayor consumidor de los productos industriales alemanes, muy por encima de los productos de Estados Unidos, China y Japón (esto es, intercambios comerciales en términos de valor económico, no de volumen).

\section{GRÁFICO 1}

Competitividad de Alemania, Italia, España, Portugal y Grecia, 1995-2015

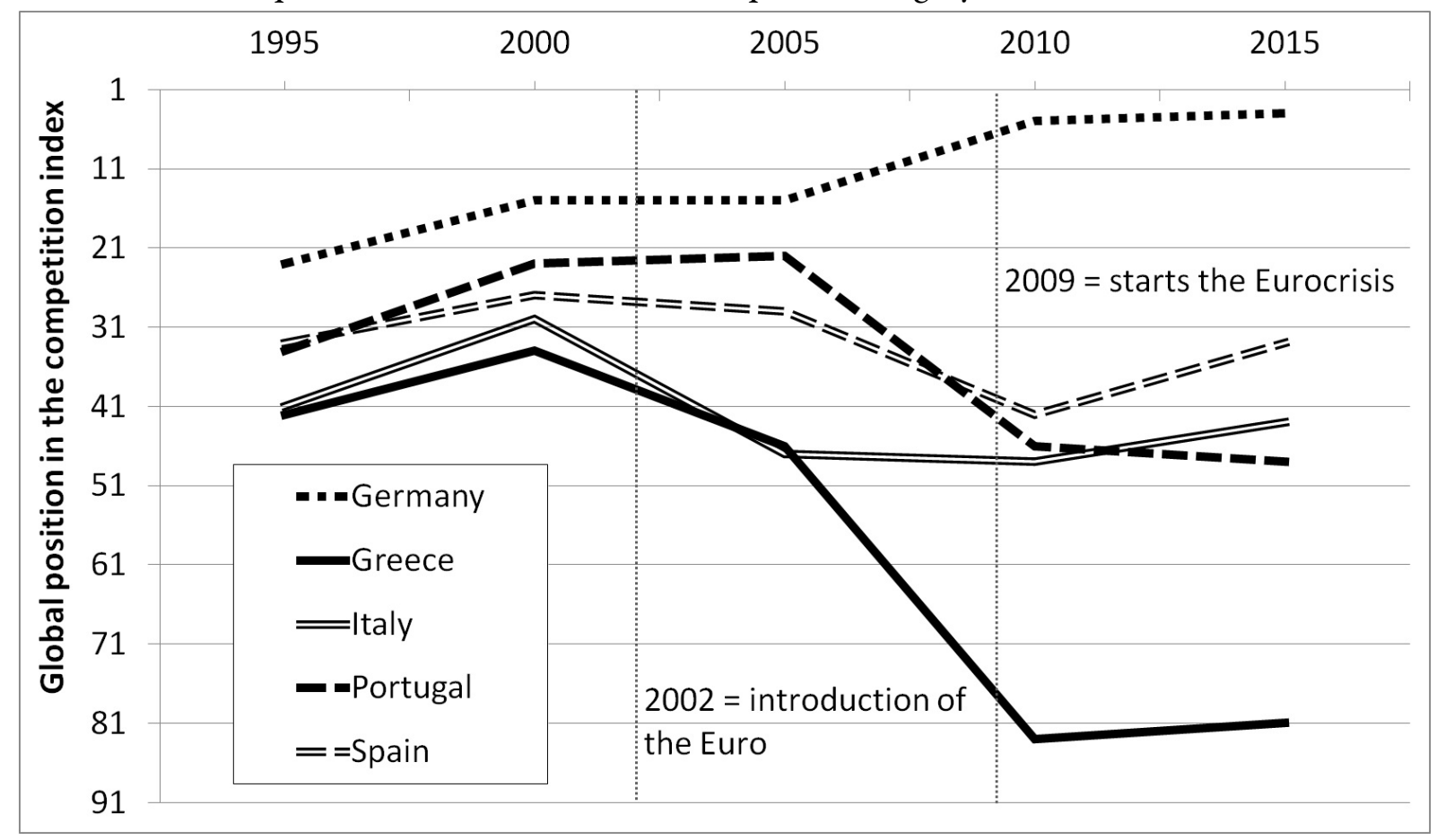

World Economic Forum (2016), "The Global Competitiveness Index Historical Dataset”, en World Economic Forum - Competitiveness Rankings 


\section{GRÁFICO 2}

Valor de las exportaciones alemanas al sur de Europa (Grecia, Italia, Portugal y España), los Estados Unidos, China y Japón, 1995-2007

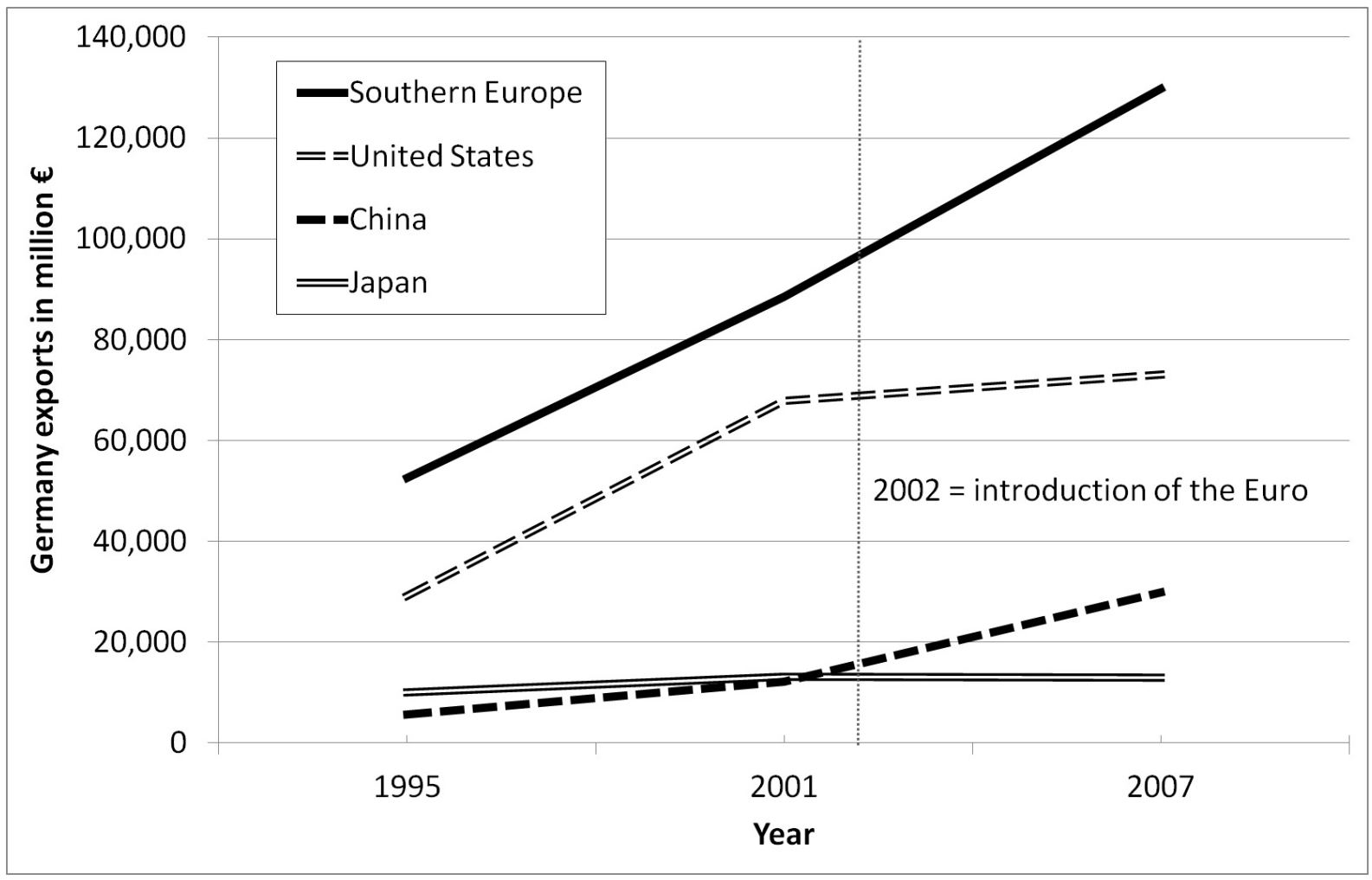

Eurostat (2011), External and Intra-European Union Trade - Statistical Yearbook

El balance comercial posterior fue muy negativo para los países del sur de Europa, y esa ha sido la principal explicación en términos del desarrollo geográfico estructural de sobreacumulación y déficits en regiones particulares. En el gráfico 1, que cuenta con estadísticas a nivel nacional (considerar aquellas a nivel regional traería mayores complicaciones para el análisis), tengan en cuenta una cuestión muy importante: cuando vemos el gran déficit de España aquí, esto no es solamente España, sino regiones particulares del país. Y esto es algo muy importante, que los economistas con frecuencia no toman en cuenta. El resultado fue el balance fiscal negativo para las cuentas nacionales. Como dije previamente, la reducción de impuestos para los ricos -debido a la ideología neoliberal- y la introducción del euro como un tipo de moneda que permite la transferencia de dinero y beneficios de un país a otro, de un banco a otro, generaron un desbalance fiscal. Para 2009 todos los países del sur de Europa estaban en problemas.

Pero debemos ser muy cuidadosos de no culpar solamente a las fuerzas políticas externas y a la burguesía, a Alemania, a los Países Bajos, al FMI... Okey, esos son los chicos malos. Pero, ¿qué pasa con la burguesía doméstica, con los chicos malos domésticos que son parte de la historia? Porque a lo largo de estos años se volvió muy claro que la burguesía doméstica estuvo esperando la crisis, como un regalo de los dioses, en aras de implementar todas esas políticas en contra de los trabajadores que hubieran sido imposibles de aplicar bajo normas verdaderamente democráticas. Hay un eslogan muy conocido que dice que las crisis generan oportunidades. Pero, ¿oportunidades para quién?, ¿y a qué costo? Voy a terminar con esta caricatura sobre Grecia (figura 3). Aquí pueden ver a Christine Lagarde, del FMI; el doctor W. Sch\#uble, ministro de finanzas de Alemania; y éste [señala la imagen] es un ejército medieval tratando de atacar el castillo de Grecia. Pero aquí está la burguesía griega, que abre una pequeña puerta, y dice “ipst! ¡Pasen por aquí! Este es el camino más simple".

Gracias por su atención. 
FIGURA 3

Christine Lagarde y el Dr. W. Sch\#uble atacando el castillo griego

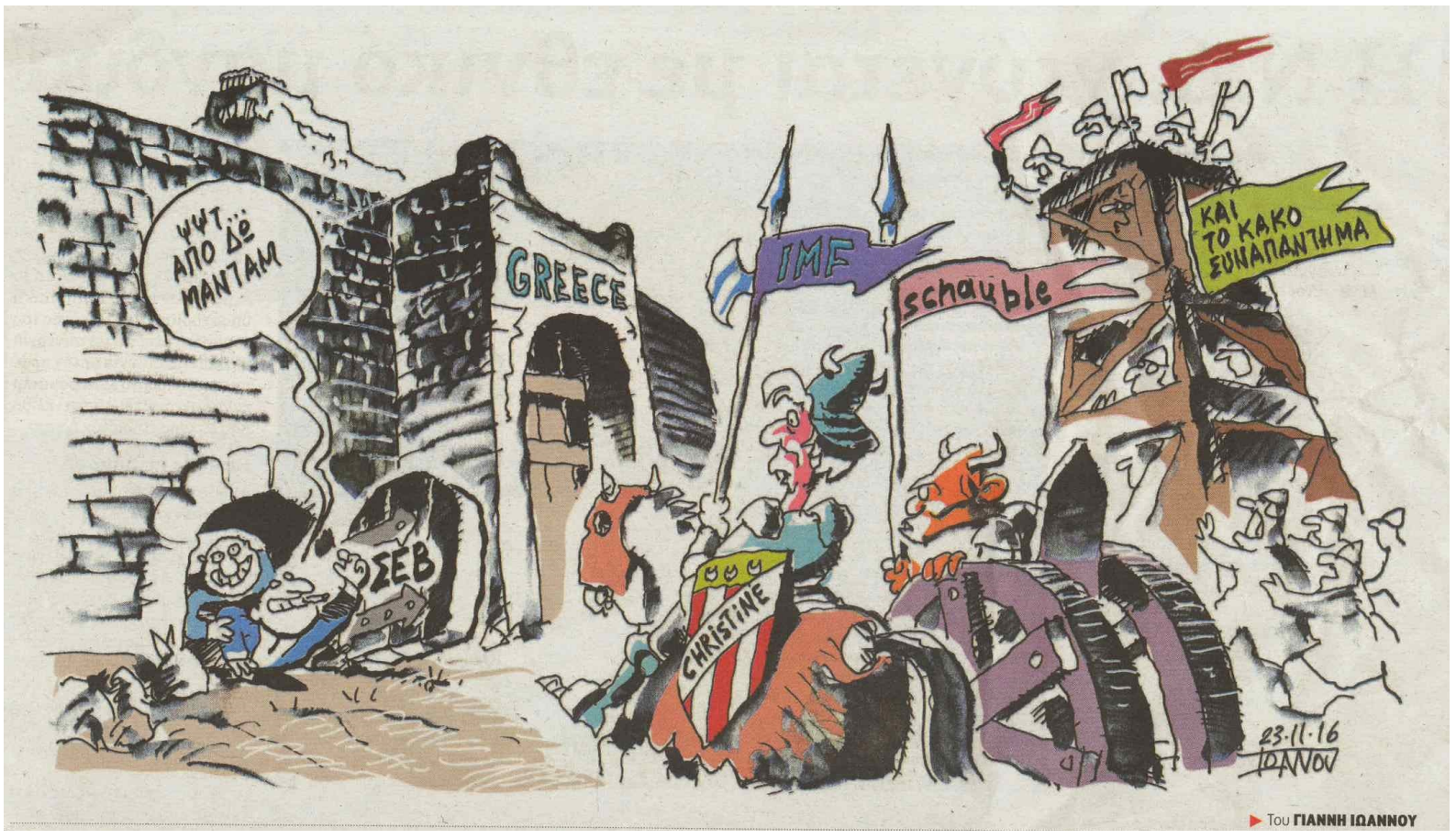

Fuente: www.efsyn.gr/ioannou

Credit: Y. Ioannou, Efimerida ton Syntakton

\section{DEBATE:}

\section{¿Podrías caracterizar la situación actual en la UE?}

Es muy muy mala. La UE está bajo la presión de las políticas de ajuste, por un lado, y en un momento de crecimiento de movimientos nacionalistas, xenofóbicos y fascistas por el otro. La combinación de crisis económica con crisis de migración y de refugiados llevó a un debilitamiento de la legitimidad de la UE en sí misma, y de los pilares políticos centrales del proyecto: los liberales y los socialdemócratas. Esas dos "familias políticas" europeas están en una gran crisis de legitimidad. El ejemplo clásico acá es Alemania, donde la gran coalición se está partiendo y un partido criptonazi muy fuerte como el AfD (Alternativa para Alemania) está creciendo. Y lamentablemente, en medio de esta crisis las voces de la izquierda son muy débiles. Esta crisis de legitimidad de los principales partidos políticos también ha afectado a los partidos de izquierda, porque todos esos años de ajuste, con crecimiento del desempleo, desalojos y abandono por parte del estado, generan sentimientos de desconfianza hacia las principales identidades políticas, y eso tiene un efecto incluso sobre la izquierda. Parece entonces que la gente se está volcando hacia cuestiones que consideran como "identidades estables”, como etnicidad, cultura, religión e idioma. Es lo que ocurre, por ejemplo, en Cataluña, o en Bélgica, y tenés estos movimientos racistas y xenofóbicos como la Lega (Nord) en Italia, el Amanecer Dorado en Grecia, el AFD en Alemania; el canciller austríaco actual es el político más reaccionario, xenófobo y racista que podrías imaginarte. Y el caso más reciente es Suecia, adonde la social democracia perdió las elecciones tras más de 65 años en el poder ¡Era impensable que la gente en Suecia votara a un partido de derecha y xenófobo! Y esto tiene que ver también con el Brexit. ¿Creés que el Brexit tiene que ver con este estúpido partido UKIP que promueve ideas nacionalistas? Eso tiene muy poco que ver. La mayor parte de los votos por el Brexit vino de áreas fuera de las grandes ciudades, de regiones previamente industrializadas afectadas por las políticas de desindustrialización y privatización de Thatcher, adonde la gente se quedó sin trabajo, en regiones como el noreste de Inglaterra, Escocia y Gales. Yo creo que el Brexit está más relacionado a una 
reacción de la gente que lleva años sufriendo por la pérdida de sus empleos, de la seguridad social, y de su propia identidad como trabajadores. Más que querer votar sí por el Brexit, se trató de una especie de mensaje de repudio a los liberales y los conservadores. Los laboristas lograron cierto éxito con Jeremy Corbyn, pero el partido está fuertemente dividido.

Sería bueno que el profesor comentara cómo entiende el concepto de financiarización, porque nos parece interesante pensar si hay una diferencia en torno al desarrollo desigual entre aquel que se da desde los países centrales hacia los países periféricos de Europa, en función del diseño de la Unión Europea, y aquel que se da entre los países de América Latina y los países centrales a nivel mundial. ¿̇Hay una especificidad en el proceso de financiarización, o el concepto es equivalente para todos los espacios en los que el capital se despliega?

Hay grandes diferencias. Una de ellas es que los países del sur de Europa han perdido, en el proceso de integración a la Unión Europea y a la zona euro, mucha de su capacidad productiva. La financiarización empezó en los años noventa, no fue sólo a causa del euro. Pero, de repente, muchos bancos del sur de Europa tuvieron mucho dinero cuyo origen era el capital excedente de los países del centro de Europa, para ser usado de una manera muy especulativa. La financiarización en Europa se dio de la mano de otras actividades especulativas, particularmente por la obtención de beneficios de las rentas antes que de la producción como los bienes raíces, las burbujas inmobiliarias en España y Grecia, y ese tipo de cuestiones-. La principal diferencia con la financiarización en los países centrales de Europa (Alemania, Países Bajos) es que en éstos se dio de la mano de la industrialización y producción de nuevas tecnologías. La financiarización en el sur se dio sin esos factores.

En relación a la burguesía griega que abre la puerta (en el dibujo), y teniendo en cuenta el rol de la banca offshore, ¿es parte de la imaginación del autor, o parte del proceso de acumulación de esa burguesía está fuera de Grecia?

No es imaginación, es una realidad. Sólo para darles un ejemplo: la fracción más importante de la burguesía griega es el capital propietario de las flotas comerciales, las cuales circulan con diferentes banderas, entre ellas la griega. La flota comercial griega es la tercera en poder, tamaño y capacidad a nivel mundial, y la más importante de Europa. A través de esta clase burguesa internacionalizada (porque pocos de estos ladrones viven en Grecia, la mayoría está en el exterior), otras fracciones del capital menos poderosas transfieren dinero al exterior -usándola como mediadora-.

Alrededor de la crisis de la zona euro existen distintos puntos de vista para explicarla. Uno de ellos es el de John Agnew, quien sostiene que buena parte del problema del desarrollo desigual en Europa es que el diseño institucional de la Unión Europea reproduce un modelo alemán, cuya experiencia histórica es la del período de la segunda posguerra, y cuya doctrina económica es el ordoliberalismo. Se trata de una doctrina que toma como experiencia histórica el fracaso de la República de Weimar y sus crisis hiperinflacionarias, que llevaron luego al nazismo. Vale la pena preguntarse si las políticas de austeridad actuales, que buscan evitar la inflación, no están llevando a lo mismo. Es decir, al ascenso de los movimientos de extrema derecha en todo el continente, habida cuenta de que las resistencias por izquierda a este modelo están fracasando. ¿Está de acuerdo con esta interpretación?

Bien, conozco la interpretación de John Agnew. Desde mi punto de vista, es parcialmente correcta. Él está en lo cierto al decir que la versión dominante del neoliberalismo en Europa es la alemana, el ordoliberalismo. Tiene razón en esto. Como sabrán, el ordoliberalismo no es una teoría nueva, se remonta a los años treinta, y fue formulada por economistas y abogados de la Universidad de Heidelberg. Agnew tiene razón en que la obsesión del ordoliberalismo con la inflación se debe a la república de Weimar. Pero no tiene en cuenta que la ultraausteridad impuesta por el ordoliberalismo no genera inflación pero genera mucho enojo y muchas obsesiones en gente que ha sido desempleada, que ha sido excluida del mercado laboral, que ha sido empobrecida. Quiero decir, Alemania tiene un $13 \%$ de gente muy pobre, lo cual es increíble para un país tan rico. Y Agnew no tiene en cuenta la incorporación de la antigua Alemania Democrática en la Alemania 
Federal. No fue sólo una incorporación, fue una invasión, una verdaderamente trágica reintroducción del capitalismo que destruyó todo. Por lo tanto, la marginación impuesta de la Alemania del este fue muy beneficiosa para la burguesía alemana porque generó, digamos, una colonia interna. Es por eso que mucha gente no sólo siente marginación, sino que siente que ha sido expuesta a la pobreza extrema, y se siente perdida en su propio país. Y vuelven hacia atrás al nazismo. Entonces, la ideología nazi es reintroducida no por una crisis de inflación, sino como resultado de las políticas de ultraausteridad y de la explosión de lo que era la Alemania democrática.

Cuando usted habla de desarrollo desigual entre Europa del Norte y del Sur, y de la introducción del euro, usted daba el ejemplo del precio del café. ¿Esto sería una especie de devaluación encubierta para que la población no se dé cuenta?

De alguna manera se puede explicar como una devaluación. Pero la devaluación estuvo enfocada en el costo del trabajo y de la reproducción social, más que en términos generales. Entonces, la devaluación fue social y espacialmente específica.

Siguiendo con lo anterior, y teniendo en cuenta el concepto de la economía liberal de estancamiento secular, ¿Grecia fue un plan piloto como política de respuesta frente a la crisis, o es un caso aislado?

En principio no fue solamente Grecia, que fue el caso más extremo. Se puede ver un uso similar en Italia, de la que no hemos hablado. Puedo ver a los países del sur de Europa como un modelo de imposición no sólo del neoliberalismo, como pasó en América Latina con las dictaduras militares, sino como un nuevo régimen de control a través de la deuda pública. Porque cada fase del desarrollo capitalista usa un arma distinta para imponer su dominación. Vivimos en la era de la financiarización, y las armas son las de las estructuras financieras. Esta fase del capitalismo está usando la deuda como una especie de oportunidad para intervenir en la reproducción social local y dañar a un lugar y a un grupo social particulares. Y creo que el sur de Europa ha sido un caso de estudio muy útil para que las fuerzas capitalistas dominantes a nivel global probaran la aplicación de sus nuevas armas, y cómo sería el efecto en sus propias sociedades.

Yo quisiera agregar que aqui pasó lo mismo. Durante los años ochenta los paises centrales, el FMI, intentaron imponer las politicas neoliberales a nuestros países por la deuda. Y de hecho la segunda ola de politicas neoliberales en Argentina se impone como condición a través de la deuda. Los planes de ajuste estructural se aplican con la excusa de que tenemos una deuda y que tenemos que reorganizar nuestras economias para poder pagarla. Hacia fines de los noventa, cuando entramos en crisis verdadera, esto se profundiza. Quizás hay algo para aprender de abi.

Usted habló sobre las múltiples causas que generaron la crisis en Grecia (la cuestión financiera, el mercado de trabajo, las privatizaciones). Me gustaría que pudiera comentar cuáles fueron las acciones multinacionales previas, contemporáneas y posteriores a la crisis. ¿Cuál es el origen de este capital? Y, luego, está este problema que tenemos en el marxismo, o en algunos marxismos, de que no podemos todavía asociar el capital financiero con el capital productivo. Por ejemplo, en Argentina, las grandes empresas multinacionales son empresas financieras. Entonces me gustaría que explicara ese punto. Y por otro lado, en el plano político, quería preguntarle por la consecuencia organizativa popular de esta crisis, y quería pedirle que comentara la situación actual.

Comenzando por la primera pregunta, uno de los efectos de la crisis es que muchas de las multinacionales que tenían actividad en el sur de Europa se fueron. No sólo firmas americanas sino también europeas. España sufrió el cierre de varias fábricas europeas de automóviles; lo mismo sucedió en Portugal. En Grecia no sucedió con una fábrica europea sino con una japonesa, pero era una pequeña. Es cierto también que todas las grandes empresas están comprometidas en actividades financieras también. La distinción entre capital financiero y productivo no siempre es posible. Pero esto es cierto también para otros sectores. Por ejemplo, el mercado de bienes raíces no puede operar sin la asistencia financiera de los bancos. Y los consumidores no pueden comprar un nuevo departamento si no toman un crédito de un banco. Entonces, la producción de viviendas en su conjunto depende de la financiarización. Sobre el segundo punto, el de la respuesta social a la crisis, 
nuevamente ésta fue muy desigual, social y geográficamente. Hubo una respuesta fuerte y militante en Grecia y España, un poco menor pero aún así importante en Portugal, y no muy significativa en Italia. Por supuesto, se puede explicar esta desigual respuesta social por los efectos desiguales de la crisis. En Grecia el efecto fue mayor, por lo que la gente se movilizó más. En España sucedió lo mismo, pero fue menor en Portugal, y menor aún en Italia. Pero por primera vez en muchas décadas, nos resultó grato ver una suerte de cooperación sursur entre fuerzas militantes. Entonces cada vez que había una manifestación en alguna ciudad europea, miles de militantes se unían en manifestaciones locales. Recuerdo que en 2001, en la manifestación principal en Génova contra el G8 éramos alrededor de dos mil griegos participando, lo mismo de España y Portugal. Fue la manifestación en la que tuvimos la primera muerte en la lucha europea, la de Carlo Giuliani. Cuando fue la ocupación de las plazas, en la Puerta del Sol (Madrid), en la Plaza de Syntagma (Atenas), en la Plaza de Rossio (Lisboa), se conformó una red de trabajo entre militantes, con expresiones en otras ciudades como Barcelona, Córdoba, Sevilla. Y esas redes aún existen, están muy vivas y bien organizadas. Estoy muy contento de ver a mis estudiantes, y a los estudiantes de otros colegas en Madrid, Barcelona, Lisboa, Porto, y así, teniendo sus propios contactos y redes para futuras colaboraciones, o discutiendo los problemas de Europa con sus propios ojos, no con los de un viejo como yo. Porque si hay esperanza en Europa, vendrá de esas nuevas generaciones. Nosotros hicimos lo que hicimos; estuvo lleno de errores; ahora veamos si esta generación de jóvenes puede hacerlo mejor.

Por último, quería preguntarle por qué la Unión Europea fue la forma de imponer el neoliberalismo en el sur de Europa

Tenemos una manera particular de imponer, no exactamente el neoliberalismo, sino el ordoliberalismo, su versión alemana. Y fue una manera muy geográfica, al usar diferentes escalas. ¿Qué quiere decir esto? Así como tenemos la producción del espacio, tenemos la producción de escalas. La escala es producida socialmente. Por ejemplo, hoy estoy aquí en La Plata, pero puedo pensar en lo que haré la semana que viene de regreso a mi universidad en Atenas. Ustedes me están escuchando hablar en inglés, están pensando en castellano, entonces eso es una producción de diferentes escalas, incluso en esta misma aula. Entonces estamos viendo a Europa ahora como la producción de un nuevo espacio y una nueva escala. Y esto opera a distintos niveles, que están siempre interconectados. El capital puede fluir libremente a través de esos espacios y escalas, pero no ocurre lo mismo con el trabajo. Entonces la astucia del ordoliberalismo se basa en una observación muy simple: el conflicto capital/trabajo y la reproducción social del trabajo tienen lugar principalmente a una escala local o regional. Por lo tanto, aunque la producción de la escala de la Unión Europea y de la zona euro se dio para que el capital fluyera libremente a lo largo de ella, y saltando de ella, impuso un tipo de dificultad para el trabajo y las masas para hacer lo mismo. Sabemos que la unificación nunca es exitosa sin movimiento de la mano de obra, y el movimiento de mano de obra en la UE es mucho menor en comparación con la movilidad en Estados Unidos u otros países grandes. Por empezar, hay diferencias culturales muy importantes. Alguien que vive en Grecia y sólo tiene en sus manos su fuerza de trabajo, no habla alemán y no puede trasladarse a Alemania para trabajar. Lo mismo pasa con los italianos y portugueses. No es casual que sean las personas multilingües y muy instruidas las que se desplacen. Y no es accidental que cuando la movilidad del trabajo en Estados Unidos es de 1,6 \% por año (es decir, el porcentaje de trabajadores que se desplazan para trabajar de un estado a otro), en Europa esa cifra es del 0,06 \%. Por lo tanto, el eslogan de la libre movilidad del capital y el trabajo es una frase vacía. Estoy hablando de fuerza de trabajo manual, no de personal científico o mano de obra calificada. La producción de escalas tiene otras implicancias. Es una cuestión muy importante y necesitaría más tiempo para explicarlo. Pero déjenme decirles solamente esto: si hay algún futuro para la Unión Europea -el futuro de la Unión Europea en el que yo creo; el que vale la pena, la esperanza y la lucha-, no vendrá de mi generación, sino de la generación de esos chicos que estaban ocupando las plazas y peleando en las calles todos estos años durante la crisis.

Muchas gracias.

Traducción y transcripción: Nicolás Trivi. 


\section{INFORMACIÓN ADICIONAL}

18 de octubre de 2018: Jornadas Platenses de Geografía y XX Jornadas de Investigación y Enseñanza en Geografía. Edificio Sergio Karakachoff. Universidad Nacional de La Plata. 